\title{
Black Esophagus in the Setting of Diabetic Ketoacidosis: A Rare Finding from Our Institution
}

\author{
Sara Ghoneim ${ }^{a} \quad$ Aun Shah $^{\mathrm{a}}$ Shaman Dalal ${ }^{\mathrm{a}} \quad$ Marc Landsman $^{\mathrm{b}}$ \\ Annette Kyprianou ${ }^{b}$ \\ aDepartment of Internal Medicine, Case Western Reserve University at MetroHealth Medical Center, \\ Cleveland, $\mathrm{OH}, \mathrm{USA}^{\circ}{ }^{\text {b}}$ Division of Gastroenterology and Hepatology, Case Western Reserve \\ University at MetroHealth Medical Center, Cleveland, OH, USA
}

\section{Keywords}

Black esophagus · Acute esophageal necrosis - Esophagogastroduodenoscopy · Diabetic ketoacidosis

\begin{abstract}
Acute esophageal necrosis (AEN) is defined as necrosis of the esophageal mucosa seen as diffuse black discoloration of the distal esophagus on an upper endoscopy. The prevalence of the disease is rare and reported to be up to $0.2 \%$ in autopsy series. The etiology of the disease is thought to be multifactorial and due to ischemic insults to the esophagus with gastric acid reflux further damaging the vulnerable mucosa. Patients are often critically ill or with significant comorbidities. Here, we present a case series of 3 patients with AEN induced by diabetic ketoacidosis.

(c) 2019 The Author(s)

Published by S. Karger AG, Basel
\end{abstract}

\section{Introduction}

Acute esophageal necrosis (AEN), also known as black esophagus or necrotizing esophagitis, is a rare severe disease of the esophagus affecting only the distal esophagus [1-6]. The etiology of the disease is thought to be multifactorial [1,4-7]. It has been postulated that gastroesophageal acid reflux disrupts the intrinsic mucosal barriers of the esophagus and causes mucosal injury, while the limited blood supply of the distal esophagus can lead to esophageal necrosis when there is hemodynamic instability. Those who suffer from AEN often have significant comorbidities or are critically ill $[8,9]$. Septic shock or acutely decompensated heart failure can lead to hypoperfusion states that predispose patients to necrotizing esophagitis [2-4]. Diabetes mellitus leads to significant microvascular disease that 


\section{Case Reports in Gastroenterology}

\begin{tabular}{l|l}
\hline Case Rep Gastroenterol 2019:13:475-480 \\
\hline DOI: 10.1159/000504434 & $\begin{array}{l}\text { ( ) 2019 The Author(s). Published by S. Karger AG, Basel } \\
\text { www.karger.com/crg }\end{array}$
\end{tabular}

Ghoneim et al.: Black Esophagus in the Setting of Diabetic Ketoacidosis: A Rare Finding from Our Institution

can be a substrate for the development of esophageal necrosis in a subset of patients [1-5]. The prevalence of the disease is reported to be up to $0.2 \%$ in autopsy series [1-3]. The endoscopic findings are striking with circumferential black discoloration seen only in the distal esophagus [1-7]. Patients present with signs of upper gastrointestinal bleeding, such as hematemesis or melena. Here, we report a case series of 3 patients from our institution who were found to have AEN induced by diabetic ketoacidosis.

\section{Case Report}

Case 1

A 67-year-old female presented to our institution with symptoms of nausea and vomiting. Initially, the vomitus was nonbilious but progressed to hematemesis. She denied melena. She had worsened speech and difficulty ambulating. The patient's medical history included hypertension, multiple cerebrovascular accidents, and invasive ductal carcinoma treated 1 year prior. She had no personal history of diabetes. On presentation, she was afebrile, hypotensive $(85 / 60 \mathrm{~mm} \mathrm{Hg}$ ), tachycardic (105 beats per $\min [\mathrm{bpm}]$ ), and tachypneic (24 breaths per min [breaths/min]). Physical exam findings included dry mucus membranes and coffee ground-like substance around the mouth. The abdomen was mildly tender, nondistended, and without guarding. Laboratory findings were significant for leukocytosis 15.3 $(\mathrm{K} / \mu \mathrm{L})$, elevated serum glucose $(1,1914 \mathrm{mg} / \mathrm{dL})$, and low serum sodium $(120 \mathrm{mmol} / \mathrm{L})$, chloride $(81$ $\mathrm{mmol} / \mathrm{L})$, and bicarbonate $(18 \mathrm{mmol} / \mathrm{L})$. Urine sample was positive for ketones, and serum beta-hydroxybutyrate (BHB) was elevated (2.74 mmol/L). Arterial blood gas showed acidosis (pH 7.19) with an elevated partial pressure of carbon dioxide $(55.1 \mathrm{~mm} \mathrm{Hg}$ ) and a reduced partial pressure of oxygen (73 mm Hg). No acute intracranial pathology was seen on a noncontrast computed tomography (CT) of the head. The patient was diagnosed with diabetic ketoacidosis. She was placed on supplemental oxygen and resuscitated with intravenous fluids. She was also administered insulin and a proton pump inhibitor (PPI) by intravenous infusion. The patient underwent esophagogastroduodenoscopy which showed circumferential black esophagus noted from $21 \mathrm{~cm}$ to the gastroesophageal junction with mucosal sloughing (Fig. 1). Biopsy findings were consistent with AEN without infectious or malignant etiology. The patient continued to improve with conservative management. She was subsequently discharged from the hospital in a stable condition without any long-term sequelae.

\section{Case 2}

During the same month, a 78-year-old female was admitted with severe right upper quadrant pain that radiated to the epigastric region and back associated with nausea and nonbilious vomiting. Her medical history was significant for chronic pancreatitis, congestive heart failure, and poorly controlled type 2 diabetes. She underwent a remote cholecystectomy. On admission, the patient was febrile $\left(39.3^{\circ} \mathrm{C}\right)$, hypertensive $(159 / 73 \mathrm{~mm} \mathrm{Hg})$, tachycardic $(120 \mathrm{bpm})$, and tachypneic (23 breaths/min). She appeared to be in severe distress. The epigastric and right upper quadrant regions were very tender to palpation. Serum chemistries showed an elevated serum glucose $(369 \mathrm{mg} / \mathrm{dL})$, low serum sodium (131 $\mathrm{mmol} / \mathrm{L})$, chloride $(94 \mathrm{mmol} / \mathrm{L})$, and bicarbonate $(19 \mathrm{mmol} / \mathrm{L})$. Urine sample showed ketones, while serum BHB was elevated $(1.64 \mathrm{mmol} / \mathrm{L})$. CT of the abdomen revealed duodenal thickening. The patient was diagnosed with diabetic ketoacidosis and started on the appropriate treatment. She continued to vomit despite the use of anti-emetics, bowel rest, and diabetic ketoacidosis treatment. A nasogastric tube was placed with aspirate showing coffee ground-like content. Gastroenterology service was consulted, and she was started on a PPI infusion and underwent an upper endoscopy which showed a distally black esophagus (Fig. 2). The patient's symptoms gradually improved, and she was able to tolerate an oral diet. She was discharged on a high dose of PPI for 3 months in addition to an appropriate diabetic medication regimen. 


\section{Case Reports in Gastroenterology}

\begin{tabular}{l|l}
\hline Case Rep Gastroenterol 2019:13:475-480 \\
\hline DOI: 10.1159/000504434 & $\begin{array}{l}\text { @ 2019 The Author(s). Published by S. Karger AG, Basel } \\
\text { www.karger.com/crg }\end{array}$ \\
\hline
\end{tabular}

Ghoneim et al.: Black Esophagus in the Setting of Diabetic Ketoacidosis: A Rare Finding from Our Institution

Case 3

A 35-year-old male with a past medical history of poorly controlled type I diabetes was admitted with melenic stool, malaise, chills, and dry cough for 1 week. He had poor appetite and did not take his scheduled insulin doses. His past medical history was also significant for esophageal candidiasis and an episode of emphysematous gastritis. On admission, vitals were concerning for hypothermia $\left(34.3^{\circ} \mathrm{C}\right)$, hypotension (blood pressure 84/48 $\mathrm{mm} \mathrm{Hg}$ ), tachycardia (109 bpm), and tachypnea (29 breaths/min). The abdomen was soft and nontender. Digital rectal exam was positive for melenic stools. Laboratory findings were significant for leukocytosis $(22.6 \mathrm{~K} / \mu \mathrm{L})$, elevated serum glucose $(428 \mathrm{mmol} / \mathrm{L})$ and serum potassium $(6.2 \mathrm{mmol} / \mathrm{L})$, low serum sodium $(128 \mathrm{mmol} / \mathrm{L})$, chloride $(104 \mathrm{mmol} / \mathrm{L})$, and bicarbonate $(5 \mathrm{mmol} / \mathrm{L})$. Urine sample was positive for ketones, and serum BHB was elevated $(0.70$ $\mathrm{mmol} / \mathrm{L}$ ). Arterial blood gas showed acidosis ( $\mathrm{pH}$ 6.92) with low partial pressures of carbon dioxide (15.5 mm Hg) and oxygen (55 mm Hg). The patient was started on broad spectrum antibiotics and micafungin, given his prior history of esophageal candidiasis and unclear source of infection leading to septic shock. He was resuscitated with intravenous fluids and administered insulin and PPI by infusion. He subsequently underwent an upper endoscopy which revealed a black esophagus with mucosal sloughing. Biopsies of the site of necrosis showed acute inflammatory exudates with necrotic cells and numerous fungal hyphae. The patient was continued on micafungin for 2 weeks and transitioned to twice daily oral PPI. A repeat esophagogastroduodenoscopy several months after discharge showed complete recovery (Fig. 3).

\section{Discussion}

AEN is a rare cause of severe injury to the esophagus [7-13]. It has an endoscopic appearance characterized by diffuse, circumferential black discoloration of the mucosa that affects the distal esophagus and stops abruptly at the gastroesophageal junction [1-7]. The etiology of the disease is unclear but thought to be multifactorial owing to the complex relationship between the esophagus' intrinsic mucosal barriers and segmental vascular supply [8-10]. It is hypothesized that due to the smaller caliber of lower segment feeding vessels, corresponding areas of the distal esophagus are predisposed to more ischemic insults and necrosis during hypoperfusion states. A "two-hit" model has been proposed and identifies ischemia as the key player in the manifestations of the disease, with some form of gastric outlet obstruction perpetuating the causative insult of reflex acid and contributing to the breakdown of mucosa [6-13]. A neutrophilic response then ensues as a result of epithelial damage or secondary to infection. Histological findings show areas of complete mucosal necrosis without residual squamous mucosa [6]. Poor nutritional status and general deconditioning may also contribute to reduced mucosal buffering and may potentiate the mechanisms by which esophageal necrosis is accelerated [5, 11-13]. The diagnosis is achieved by visualizing the blackened segment of the esophagus with biopsies obtained to exclude other etiologies [1-14]. Black esophagus affects men more so than women with a peak incidence in the sixth decade of life [2,14]. Multiple comorbidities increase the likelihood of AEN. Specifically, hyperglycemia is seen in almost $90 \%$ of patients with this condition [12-15]. All of our patients had underlying comorbidities that predisposed them to low perfusion states, and/or microvascular vasculopathies. Further, all of them presented with diabetic ketoacidosis with subsequent endoscopic findings of AEN [12-15]. Interestingly, one of our female patients presented with diabetic ketoacidosis and necrotizing esophagitis without a prior diagnosis of diabetes mellitus. In addition, patients can often present with melena or hematemesis as we reported in our case series [4-10]. Other symptoms include dysphagia or epigastric pain [1-8]. Laboratory findings are nonspecific and are generally attributed to the underlying disease leading to the esophageal insult $[1,5-8,12-15]$. There is limited data to guide management of this disease, and it appears to be supportive. Oral intake is avoided for at least $24 \mathrm{~h}$ and diet is advanced as tolerated $[4,10]$. Nasogastric tubes are generally held unless there is 
Ghoneim et al.: Black Esophagus in the Setting of Diabetic Ketoacidosis: A Rare Finding from Our Institution

persistent vomiting $[8,15]$. The decision to initiate antimicrobial therapy has to be individualized on the basis of clinical and objective findings of serious infection or sepsis [1, 10-15]. In our case series, only 1 patient needed antifungal therapy to treat the underlying sepsis. Lastly, while the mortality rate with AEN is reported to be $23-35 \%$, it is often due to coexisting comorbidities. Fortunately, most patients achieve endoscopic resolution of the disease with supportive care only $[3-8,14,15]$.

\section{Statement of Ethics}

Informed consent was obtained for this case report.

\section{Disclosure Statement}

The authors declare that they have no conflicts of interest.

\section{Funding Sources}

No external funding was used for this case report.

\section{Author Contributions}

S. Ghoneim, A. Shah, S. Dalal, M. Landsman, and A. Kyprianou wrote, edited, and approved the final version. S. Ghoneim wrote, edited, revised, and approved the final version of the manuscript and she is the article guarantor.

\section{References}

1 Burtally A, Gregoire P. Acute esophageal necrosis and low-flow state. Can J Gastroenterol. 2007 Apr;21(4):245-7.

2 Augusto F, Fernandes V, Cremers MI, Oliveira AP, Lobato C, Alves AL, et al. Acute necrotizing esophagitis: a large retrospective case series. Endoscopy. 2004 May;36(5):411-5.

3 Shah AR, Landsman M, Waghray N. A Dire Presentation of Diabetic Ketoacidosis with "Black Esophagus". Cureus. 2019 May;11(5):e4761.

4 Moretó M, Ojembarrena E, Zaballa M, Tánago JG, Ibánez S. Idiopathic acute esophageal necrosis: not necessarily a terminal event. Endoscopy. 1993 Oct;25(8):534-8.

5 Gurvits GE. Black esophagus: acute esophageal necrosis syndrome. World J Gastroenterol. 2010 Jul;16(26):3219-25.

6 Goldenberg SP, Wain SL, Marignani P. Acute necrotizing esophagitis. Gastroenterology. 1990 Feb;98(2):493-6.

7 Bonaldi M, Sala C, Mariani P, Fratus G, Novellino L. Black esophagus: acute esophageal necrosis, clinical case and review of literature. J Surg Case Rep. 2017 Mar;2017(3):rjx037.

8 Gurvits GE, Cherian K, Shami MN, Korabathina R, El-Nader EM, Rayapudi K, et al. Black esophagus: new insights and multicenter international experience in 2014. Dig Dis Sci. 2015 Feb;60(2):444-53.

9 Averbukh LD, Mavilia MG, Gurvits GE. Acute Esophageal Necrosis: A Case Series. Cureus. 2018 Mar;10(3):e2391.

10 Day A, Sayegh M. Acute oesophageal necrosis: a case report and review of the literature. Int J Surg. 2010;8(1):6-14.

11 Kim YH, Choi SY. Black esophagus with concomitant candidiasis developed after diabetic ketoacidosis. World J Gastroenterol. 2007 Nov;13(42):5662-3.

12 Tanaka S, Fujishiro M, Ichijima R, Kohno G, Abe M, Ishihara H. Acute esophageal necrosis after cellulitis in an obese patient with diabetes mellitus. J Diabetes Investig. 2019 Jun 20. doi: 10.1111/jdi.13104 [Epub ahead of print].

13 Field Z, Kropf J, Lytle M, Castaneira G, Madruga M, Carlan SJ. Black Esophagus: A Rare Case of Acute Esophageal Necrosis Induced by Diabetic Ketoacidosis in a Young Adult Female. Case Rep Gastrointest Med. 2018 Nov;2018:7363406.

14 Shafa S, Sharma N, Keshishian J, Dellon ES. The Black Esophagus: A Rare But Deadly Disease. ACG Case Rep J. 2016 Jan;3(2):88-91. 


\section{Case Reports in Gastroenterology}

\begin{tabular}{l|l}
\hline Case Rep Gastroenterol 2019;13:475-480 \\
\hline DOI: 10.1159/000504434 & $\begin{array}{l}\text { @ 2019 The Author(s). Published by S. Karger AG, Basel } \\
\text { www.karger.com/crg }\end{array}$ \\
\hline
\end{tabular}

Ghoneim et al.: Black Esophagus in the Setting of Diabetic Ketoacidosis: A Rare Finding from Our Institution

15 Khan H, Ahmed M, Daoud M, Philipose J, Ahmed S, Deeb L. Acute Esophageal Necrosis: A View in the Dark. Case Rep Gastroenterol. 2019 Jan;13(1):25-31.

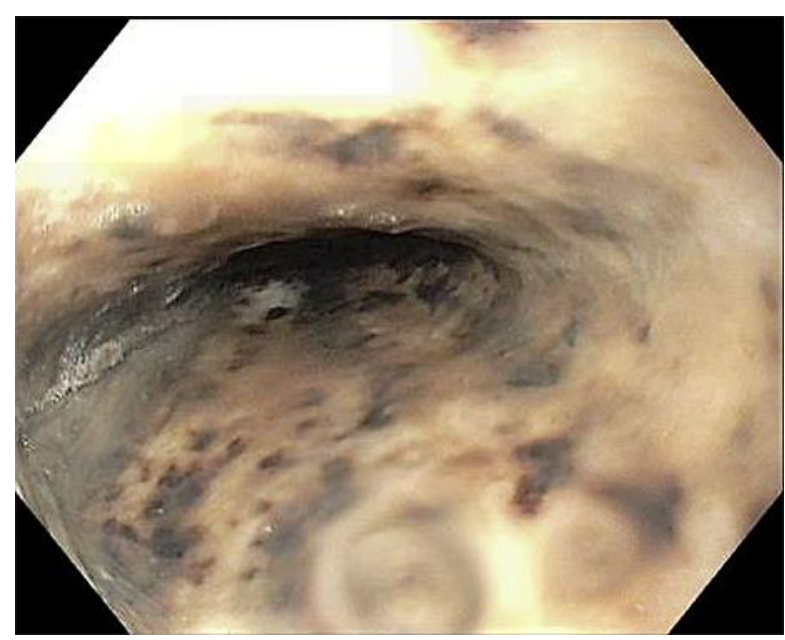

Fig. 1. Acute esophageal necrosis seen in the esophagus with circumferential black discoloration of the mucosa.

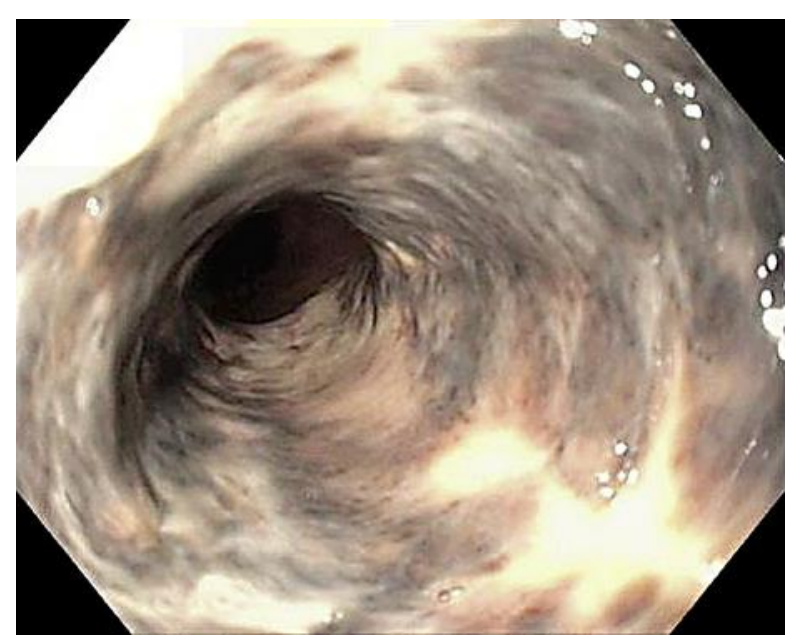

Fig. 2. Black esophagus seen in a patient who presented with diabetic ketoacidosis. 
Ghoneim et al.: Black Esophagus in the Setting of Diabetic Ketoacidosis: A Rare Finding from Our Institution

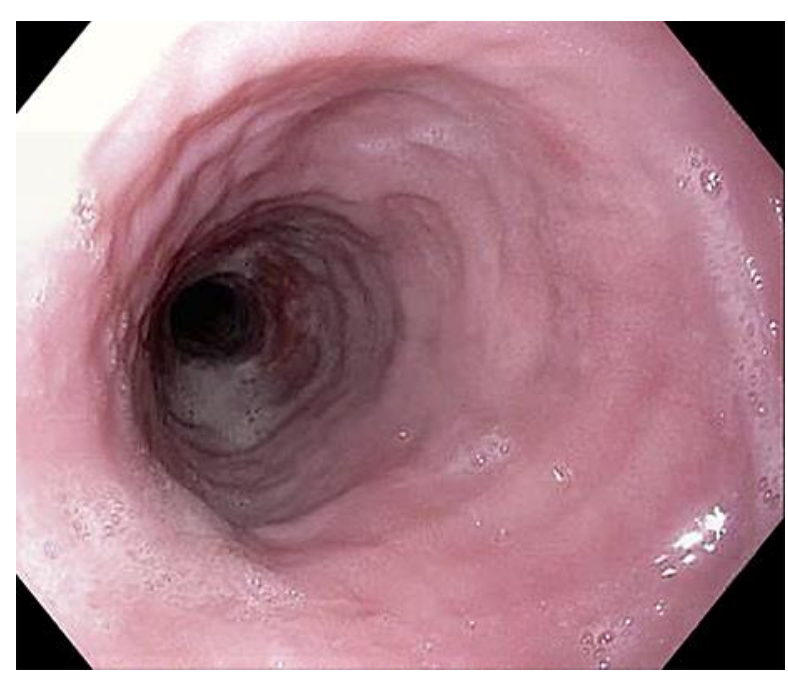

Fig. 3. Recovery of esophageal mucosa with re-epithelization seen in a 37-year-old male who initially presented with black esophagus. 